\title{
TAMING THE BEAST: MORAL VIEWS OF THE CRIMINAL LAW
}

Harm to Others. By Joel Feinberg. Oxford University Press, New York, N.Y., 1984. pp. 269. \$22.50.

Wild Justice: The Evolution of Revenge. By Susan Jacoby. Harper and Row, New York, N.Y., 1983. pp. 387. \$17.95.

\section{Reviewed by Marvin C. Henberg*}

Both Joel Feinberg's Harm to Others ${ }^{1}$ and Susan Jacoby's Wild Justice $^{2}$ are concerned generally with the relationship between morality and criminal law. Beyond this shared concern, however, the two books are vastly different in tone, temperament, style, and method. Addressing an idealized audience of legislators, ${ }^{3}$ Feinberg adopts a Platonic view of the challenge taken up by the criminal law: how a few rational philosophical guardians can devise rules in restraint of a beastly multitude. ${ }^{4}$ Jacoby, by contrast, views the main challenge of criminal law as restraint of the beast inside each of us, guardians included. Accordingly, Feinberg's tone is patient and elevated, his arguments etched in a patina of careful distinctions, whereas Jacoby's tone is hurried and even strident, her arguments borne by winds of passion and hints of impending calamity. Where Feinberg is the meticulous host, fussing everything calmly and conscientiously into place, Jacoby is the unruly house guest, gusting in with the ardor of an Old Testament prophet. Given these disparities in their authors' outlooks, the two books are best discussed separately.

Harm to Others is the first in a projected four volume series titled The Moral Limits of the Criminal Law. The second volume, Offense to Others, has already appeared, ${ }^{5}$ while the remaining two volumes, Harm to Self and Harmless Wrongdoing, are slated for publication in 1986. The first and second volumes concentrate respectively on harm and offense, arguing that, properly interpreted, these two concepts provide legitimate moral grounds for criminal prohibition. The third and fourth volumes

\footnotetext{
* Professor of Philosophy, University of Idaho.

1. J. Feinberg, Harm to Others (1984).

2. S. JACOBY, Wild Justice: The EVOlution OF REVENGE (1983).

3. J. FEINBERG, supra note 1 , at 4.

4. Id. at 66-67 (discussing Plato's The Republic).

5. J. FeINBERG, OfFENSE To OTHERS (1985).
} 
argue that these two concepts exhaust the legitimate reach of criminal prohibition, thereby dismissing in order the doctrines of legal paternalism and legal moralism. ${ }^{6}$

In Harm to Others, Feinberg argues that harm is a useful concept for formulating a moral foundation for criminal law only when understood beyond its core sense of inflicting physical hurt. To add the infliction of psychological hurt, however, yields an inaccurate concept, for some uniquely sensitive people may be psychologically hurt by otherwise permissible actions; in addition, harms may exist independently of physical or psychological suffering, as in damage to a person's reputation without his knowledge. To overcome such difficulties, Feinberg wisely abandons the subjective criterion of suffering in favor of viewing harms as objectively determinable setbacks to interests. ${ }^{7}$

An important strength of Feinberg's analysis of legally protectable interests lies in his concept of an "interest network." Interests are far from discrete entities arranged in the relationship of a simple means to a simple end, as other analyses all too often suggest. Instead, interests are interdependent, related in complex and sometimes contrary ways. The direct setback of a welfare interest, for example, is always indirectly a setback of most of one's deeper, ulterior interests, even though a few ulterior interests may actually be advanced. Loss of financial security, for example, generally injures most ulterior interests, but may in fact enhance one's ulterior interest in having a persevering character. Judging the degree of harm, in Feinberg's view, thus involves judging the objective setback to a person's entire interest network, not simply the setback to the interests most immediately affected. Feinberg deserves high praise for working out such a relatively robust view of human choice and experience.

Interests, of course, may be frustrated by a variety of occurrences, including natural disaster, negligence, misadventure, accident, and deliberate interference on the part of others. Forced, therefore, to narrow his focus, Feinberg contends that the proper moral aim of criminal law is to prohibit only those harms that are wrongs as well as setbacks to interests. ${ }^{9}$ One is wronged in this relevant sense only when one's rights have been violated in a morally indefensible manner. Like so many others before him, Feinberg thus enters the morass of conflicting claims about the substance and status of moral rights.
6. J. FEINBERG, supra note 1, at 3-27.
7. Id. at 31-55.
8. Id. at 55-61.
9. Id. at 105-25. 
Focusing on one particularly problematic right will perhaps best convey a sense of Feinberg's method throughout Harm to Others. Contrary to what one might expect from his introductory disparagement of legal paternalism, Feinberg advocates criminal sanctions against "bad samaritanism."10 In cases where rescue will not unreasonably endanger or inconvenience a potential rescuer, Feinberg argues that failure to rescue ought to be criminalized. By thus prescribing a legal duty to rescue that transcends the bounds of special obligations-such as those of a parent or paid lifeguard-Feinberg rejects the tenet of Anglo-American law that declines to acknowledge such a duty. A traditional line of reasoning in favor of such a view, however, is not available to him; he does not assume, as others have, that the state has an interest in promoting good character among its citizens. While Feinberg may concede this interest as legitimate in guiding tax policy, he must deny that it could ever be an interest relevant to criminal law, for it is unnecessarily meddlesome, and allows governmental interference into the private sector far beyond the extent necessary to prevent wrongful harms. Feinberg must therefore argue that failure to rescue under the prescribed circumstances is (1) a harm, and (2) a violation of the moral rights of the person in need of rescue.

To establish that bad samaritanism results in harm, Feinberg argues persuasively against those who consider unobligated rescue a gratuitous benefit. ${ }^{11}$ The gratuitous benefit concept, Feinberg demonstrates, only applies to instances where person $A$ enhances $B$ 's interests and $B$ 's interests are already at or near some normative baseline. One thus gratuitously benefits another by bestowing on that individual an unanticipated gift of one hundred dollars. In contrast, if $A$ rescues $B$ from imminent death, $A$ is restoring $B$ to his baseline, not gratuitously benefiting him. Failure to rescue, then, is an act of harming, even though the failed rescuer is neither causally nor morally responsible for the victim's original plight.

Feinberg's more difficult case lies in establishing that, in the absence of special moral ties to the rescuer, a victim has a right to rescue. One potential difficulty is that an alleged right to rescue may play tunefully in the ears of the legal paternalist and the legal moralist, who will campaign to have the "right" extended to people endangered by their own conduct. A policy of forced rehabilitation of drug addicts comes immediately to mind, for the evil of addiction is no less life threatening than other types

10. Id. at $126-86$.

11. Id. at $130-48$. 
of danger. Feinberg thus courts companions-in-arms with whom he disagrees in principle.

I do not wish, however, to leave discussion of Feinberg on a critical note. Even readers who disagree with particular conclusions in Harm to Others will be impressed with the solidity and substance of the whole. Feinberg exemplifies to an admirable degree Bertrand Russell's maxim that if one is to risk being wrong, he should be wrong clearly. Happily, more often than not Feinberg is right-right usually in defending complex normative claims and right always in challenging us to ponder issues in considerable depth.

If Feinberg philosophizes with a scalpel, cutting one fine distinction after another, Jacoby borrows a page from Nietzsche to philosophize with a hammer. Given her lay audience and her insistence on the urgency of reform, Jacoby's choice of tool is appropriate. The topic of revenge, we learn at the outset, is currently taboo, treated by twentieth century men and women in the same hypocritical fashion as the Victorians treated the topic of sex. ${ }^{12}$ The revenge taboo, Jacoby obviously believes, must be assaulted frontally, its forbidden terms shouted loudly and repeatedly in an effort to desensitize sensitive ears, preparing the way for understanding. Appropriately enough, she pursues this tactic with a vengeance.

In hammering against the modern revenge taboo, Jacoby unfortunately makes more work for herself than necessary. She claims, for instance, that the term "retribution" is a virtual synonym for revenge, and thus a mere euphemism. ${ }^{13}$ Normally this charge is made only by opponents of a retributivist approach to punishment, and Jacoby is later forced to counter the charge by reintroducing the distinction she has undercut. Traditionally, retributivists define "retribution" as an approach to punishment in which acceptable moral principles serve as limits on revenge. Finding herself in need of exactly this point, Jacoby talks variously of "measured retribution,"14 "just retribution,"15 and "appropriate retribution."16 It would have been simpler-as well as more in line with current philosophical and legal usage-to honor the distinction without the qualifying adjectives.

Still, philosophizing with a hammer has its strong points. A reader would have to be comatose to miss Jacoby's main point: the convenient modern formula justice, not revenge is both simplistic and dangerous. It

12. S. JACOBY, supra note 2, at 12-13.

13. Id. at 4.

14. Id. at 11 .

15. Id. at 272 .

16. Id. at 305 . 
is simplistic because the purpose of the law is not merely to limit revenge, but also to dish it out in proper measure. The formula is dangerous because it fails to recognize that private vengeance is inevitable when the public system of punishment fails to satisfy. In contemporary America, Jacoby warns, frustration at the lack of rctribution within the court system is evident at screenings of movies such as Death Wish, where audiences cheer indiscriminate killings meted out by the vigilante hero, who, though wronged by thugs, has been more deeply wronged, the movie implies, by a failed public system of revenge. ${ }^{17}$ While there may be nothing new in the theme of revenge as a crowd-pleaser, there is a disturbing new edge to such modern manifestations of the theme as Death Wish. Earlier revenge drama, Jacoby notes, at least had the grace of pointing out that private revenge, though perhaps inevitable, was both pernicious and ultimatcly self-defeating. In Death Wish, however, the message is one of private revenge as ultimate vindication. ${ }^{18}$

Jacoby is at her best in writing about the dangers underlying such social symptoms as audience reaction to Death Wish. Despite all the supposedly enlightened talk of therapy or rehabilitation as a substitute for criminal punishment, the fact seems inescapable that punishment has symbolic value above and beyond whatever other values it may serve. The symbol is that of the scales of justice somehow balancing, and a widespread perception of imbalance can undermine the deterrent value of law, not as it protects against deliberate crime, but as it protects against vendettas for crimes that go unpunished. Jacoby does not provide the most careful analysis in the literature of crime and punishment, but she does put her finger squarely on the pulse of a growing social menace.

The canvas of Wild Justice is sprawling. Jacoby discusses ancient Greek drama, ${ }^{19}$ Old Testament prophecy, ${ }^{20}$ New Testament forgiveness, ${ }^{21}$ Jacobean theatre, ${ }^{22}$ the trial of Eichman in Jerusalem, ${ }^{23}$ the insanity defense, ${ }^{24}$ and a variety of gruesome slayings. ${ }^{25}$ Her extended treatment of each topic reflects admirable concern with historical context and cultural sensibility. Nevertheless, in the concluding chapter ${ }^{26}$ many of these topics are juxtaposed within the space of a few sentences, threat-
17. Id. at $8,174-75$ (discussing the movie Death Wish).
18. Id. at 174 .
19. Id. at 20-34.
20. Id. at 77-88.
21. Id. at 88-104.
22. Id. at $134-48$.
23. Id. at $284-89$.
24. Id. at $311-30$.
25. See, e.g., id. at 209 (discussing the Charles Manson murders).
26. Id. at 331-62. 
ening to undo some of what the author has previously achieved. Perhaps as a consequence, the book's subtitle, The Evolution of Revenge, strikes an equivocal note. Sometimes Jacoby seems to have in mind not evolution but moral progress, as when she praises the liberation of revenge from the doctrine of hereditary guilt, ${ }^{27}$ or the practice of private settlement for murder. ${ }^{28}$ At other times, however, Jacoby seems to favor a truly Darwinian application of the evolutionary metaphor: the evolution of revenge is simply the transformation of an invariant human impulse as it blindly accommodates changes-mutations-within the social structure. ${ }^{29}$ By this standard, a society must pacify the beast within as best it can, and notions of moral progress or moral evaluation seem sadly irrelevant.

Ultimately, I think, the equivocation must be resolved in favor of Jacoby's viewing the evolution of revenge primarily as a piece of moral progress punctuated by notable instances of backsliding. Despite her defense of retributive punishment, for example, she opposes the death penalty on the grounds that the state should not in one circumstance morally embrace an act that it elsewhere condemns. ${ }^{30}$ Unless some vision of moral progress infused Jacoby's thinking, the preceding argument would not make sense. If the evolution of revenge were a case of blind social accommodation, strict application of the lex talionis, life for life, could not be so emphatically dismissed.

Readers accustomed to cautious jurisprudential writings on the subject of crime and punishment may, as I have suggested, find Wild Justice something of a trial. Harm to Others would better suit their inclinations, but if I may close with an admonition, I would urge such readers, presuming time for only one book, to make Wild Justice their choice. By parity of reasoning, readers with a present taste for popular journalism ought to read Feinberg's book. None of us can afford to approach these issues according to rote, and choosing the less congenial author might engender profitable unsettling of some erroneous assumptions.

27. Id. at 120-21.

28. Id. at 125 .

29. Id. at 183-85 (discussing the persistence of the "unwritten law" of revenge as a putative justification for crimes of passion).

30. Id. at 237. 